\title{
Follow up of workers previously exposed to silver solder containing cadmium
}

\author{
H J Mason, N Williams, S Armitage, M Morgan, S Green, B Perrin, W D Morgan
}

\begin{abstract}
Objectives-To study longitudinal biological monitoring data on urinary and blood cadmium collected in a small cohort of nine workers who had been brazing for several years with solders containing cadmium.
\end{abstract}

Methods-Cadmium was measured by neutron activation analysis in livers and kidneys, and estimates of renal function were carried out in 1983 and 1995. During the intervening period exposure to cadmium was dramatically reduced by local exhaust ventilation control and substitution of the solder containing cadmium.

Results-From urinary protein measurements there was evidence within the group of increasing renal tubular damage over the 12 year period, even though exposure to cadmium was dramatically reduced over this period and almost eliminated by 1995 . There was no evidence from serum creatinine of decreasing glomerular filtration rate, and the renal tubular handling of calcium, phosphate, or urate had not worsened significantly. Blood and urinary cadmium concentrations reduced significantly over the 12 year period but were still substantial in 1995. Blood cadmium concentrations tended to reflect cadmium body burden in 1995 when exposure had been low for several years, and decreased most significantly during 1983-90. By contrast urinary cadmium concentrations only decreased significantly from about 1990 onwards. Urinary cadmium was not significantly correlated with liver or kidney cadmium concentration in either 1983 or 1995 . This may be due to the level of tubular dysfunction in the cohort. Calculated cumulative excretion of cadmium over the 12 year period was substantially greater than the loss of cadmium measured in livers and kidneys and the derived loss in body burden. Reasons for this are discussed. It is possible that in cohorts, where renal damage is apparent, urinary concentrations reflect a substantial component of current exposure rather than stored body losses.

Conclusions-The data reinforce the concept that blood cadmium concentrations may not always reflect recent exposure, but may reflect body burden derived from historical exposure depending on the degree of current exposure; and that the decline in urinary and blood cadmium measurements after removal from, or reduction in, exposure will be slow and depend on the historical body burden.

(Occup Environ Med 1999;56:553-558)

Keywords: urine; blood; retinol binding protein; liver; kidney

A group of workers exposed to silver solder that contained cadmium have been monitored for blood and urine cadmium concentrations over several years. These workers were employed in the specialist job of repairing or building the jigs that are used to hold articles that are to be painted or plated. Historically, the silver solder used for this work was high in cadmium (up to $22 \%$ ), which allowed these fragile structures to be soldered at lower temperatures. A few firms centred in the Birmingham area were involved in this work and it had been common for experienced jig welders to have been employed at several of these firms. They were historically small firms with few control measures to limit exposure to cadmium fumes. Intervention in the early 1980 s by the Health and Safety Executive - the United Kingdom's regulatory body for the protection of workers - sought initially to reduce exposure in these firms by improvement in control measures and then in the mid-1980s by substitution with solder low in, or without, cadmium. However, much of the activity was involved in repairing old jigs and therefore some low exposure to cadmium was likely even if solder with low or no cadmium was being used on new welding tasks. From the 1990s it is likely that contact with jigs containing any cadmium solder would be infrequent. Personal atmospheric monitoring in 1981 during brazing operations at several of these factories ranged between $0.005-0.55 \mathrm{mg} / \mathrm{m}^{3}$ with a mean value of $0.114 \mathrm{mg} / \mathrm{m}^{3}$. A smaller study of the industry sector in 1991 suggested that exposure had decreased during brazing with a mean (range) personal exposure of 0.007 (0.001-0.037) $\mathrm{mg} / \mathrm{m}^{3}$. Current occupational exposure limits for cadmium fume is 0.025 $\mathrm{mg} / \mathrm{m}^{3}$. $^{2}$

Monitoring of urinary and blood cadmium had been introduced for several workers in this sector between 1980 and 1982; urinary low molecular weight protein measurements $\left(\beta_{2}\right.$ microglobin initially and then retinol binding protein) were also measured at various times from 1982 to the present. In 1983 in vivo measurements of liver and kidney cadmium were performed by in vivo neutron activation analysis $^{2}$ in some of these jig-makers. In the light of the measures to reduce exposure to cadmium from the mid-1980s onwards, it was decided to repeat the in vivo measurements. 
Table 1 In vivo and body fluid cadmium and urinary retinol binding protein measurements at the times of in vivo investigations

\begin{tabular}{|c|c|c|c|c|c|c|c|c|c|}
\hline $\begin{array}{l}\text { Worker } \\
\text { No }\end{array}$ & Date & $C d(B)$ & $C d(U)$ & $\begin{array}{l}\text { Retinol binding } \\
\text { protein }(U)\end{array}$ & Cd Kidney & Cd Liver & Creatinine $(S)$ & $\mathrm{FeCa} \%$ & $\mathrm{FePi} \%$ \\
\hline \multirow[t]{2}{*}{1} & 1995 & 54 & 7.7 & 55 & 27.8 & 10.8 & 127 & 1.9 & 19.4 \\
\hline & 1983 & 174 & 21.9 & 48 & 42.7 & 46.1 & 122 & 3.0 & 7.3 \\
\hline \multirow[t]{2}{*}{2} & 1995 & 95 & 11.4 & 1421 & 32.4 & 34.7 & 120 & 7.6 & 24.2 \\
\hline & 1983 & 279 & 68.9 & 421 & 32.8 & 66.7 & 134 & 4.4 & 15.7 \\
\hline \multirow[t]{2}{*}{3} & 1995 & 53 & 6.0 & 90 & 26.0 & 0 & 85 & 1.1 & 25.2 \\
\hline & 1983 & 239 & 27.1 & 52 & 34.0 & 13.5 & 96 & 2.8 & 14.1 \\
\hline \multirow[t]{2}{*}{4} & 1995 & 130 & 10.5 & 898 & 41.7 & 52 & 149 & 4 & 14.4 \\
\hline & 1983 & 198 & 32.6 & 81 & 41.5 & 42.1 & 111 & 5.1 & 31.2 \\
\hline \multirow[t]{2}{*}{5} & 1995 & 91 & 15.8 & 2794 & 29.7 & 16.2 & 98 & 6.4 & 25.7 \\
\hline & 1983 & 219 & 22.2 & 1083 & 36.5 & 19.0 & 113 & 3.7 & 23.1 \\
\hline \multirow[t]{2}{*}{6} & 1995 & 40 & 4.6 & 356 & 16.8 & 15.7 & 104 & 2.9 & 21.6 \\
\hline & 1983 & 121 & 9.5 & 29 & 8.8 & 6.6 & 80 & 1.6 & 2.3 \\
\hline \multirow[t]{2}{*}{7} & 1995 & 119 & 21.1 & 413 & 25.8 & 10.2 & - & - & - \\
\hline & 1983 & 195 & 23.0 & 108 & 32.0 & 14.7 & 99 & 1.2 & 11.7 \\
\hline \multirow[t]{2}{*}{8} & 1995 & 140 & 14.1 & 22 & 41.2 & 24.6 & 105 & 2.8 & 25.5 \\
\hline & 1983 & 244 & 34.3 & 21 & 39.4 & 44.9 & 93 & 2.6 & 12.1 \\
\hline \multirow[t]{2}{*}{9} & 1995 & 101 & 15.0 & 74 & 56.0 & 38.1 & 99 & 2.1 & 16.7 \\
\hline & 1983 & 179 & 27.7 & 37 & 36.6 & 55.8 & 100 & 0.8 & 3.4 \\
\hline \multicolumn{2}{|c|}{$\begin{array}{l}\text { Mean } 1995 \\
\text { (range) }\end{array}$} & $\begin{array}{l}91 \\
(40-140)\end{array}$ & $\begin{array}{l}11.8 \\
(4.6-21.1)\end{array}$ & $\begin{array}{l}680 \\
(22-2794)\end{array}$ & $\begin{array}{l}33 \\
(16.8-56.0)\end{array}$ & $\begin{array}{l}22 \\
(0-52)\end{array}$ & $\begin{array}{l}111 \\
(85-149)\end{array}$ & $\begin{array}{l}3.6 \\
(1.1-7.6)\end{array}$ & $\begin{array}{l}21.3 \\
(14.4-25.7\end{array}$ \\
\hline \multicolumn{2}{|c|}{ Median } & 95 & 11.4 & 356 & 29.7 & 16.2 & 105 & 2.85 & 22.9 \\
\hline \multirow{2}{*}{\multicolumn{2}{|c|}{$\begin{array}{l}\text { Mean } 1983 \\
\text { (range) }\end{array}$}} & 205 & 29.7 & 209 & 34 & 34 & 107 & 3.0 & 13.7 \\
\hline & & $(121-279)$ & $(9.5-68.9)$ & $(21-1083)$ & $(8.8-42.7)$ & $(6.6-66.7)$ & $(90-134)$ & $(0.8-5.1)$ & $(2.3-31.2)$ \\
\hline \multicolumn{2}{|c|}{ Median } & 198 & 27.1 & 52 & 36.5 & 42.1 & 106 & 2.90 & 13.1 \\
\hline \multicolumn{2}{|c|}{$\mathrm{p}$ Value } & $<0.01$ & $<0.01$ & $<0.01$ & 0.73 & 0.074 & 0.84 & 0.38 & 0.14 \\
\hline
\end{tabular}

Blood and urinary $\mathrm{Cd}$ units are $\mathrm{nmol} / \mathrm{l}$ and $\mathrm{nmol} / \mathrm{mmol}$ creatinine, urinary retinol binding protein units are $\mu \mathrm{g} / \mathrm{mmol} \mathrm{creatinine}$; kidney and liver $\mathrm{Cd}$ are in $\mathrm{mg}$ and $\mathrm{ppm}$; fractional excretion of calcium (Ca), phosphate $(\mathrm{Pi})$, and urate are expressed as \%; urinary total protein and albumin are in $\mathrm{mg} / \mathrm{mmol} \mathrm{creatinine}$. $\mathrm{p}$ Values are derived from 1995-83 comparisons with Wilcoxon matched pairs signed ranks tests.

This was carried out in 1995 on 10 subjects still associated with jig manufacture and repair. Nine of the 10 subjects who were investigated in 1995 had been measured in 1983. These nine subjects had been under regular health surveillance and biological monitoring by the Health and Safety Executive during the 12 years between in vivo measurements At the time of in vivo measurements a further examination of renal function was carried out. These renal function tests included urinary total protein, albumin, retinol binding protein, and $\mathrm{N}$-acetyl glucosaminidase (NAG). Fractional excretion of calcium, phosphate, and urate and serum creatinine were also measured.

The in vivo measurement system used in 1995 to measure liver and kidney cadmium concentrations was not identical to that used originally but considerable effort was made to ensure that results were comparable. The calibration of the measurement systems were consistent and traceable. Analytical techniques were very similar between 1983 and 1995 for biological measurements in blood and urine; the quality control material used in 1983 was available for remeasurement in 1995 to investigate systematic changes in measurement.

Six of the nine workers measured in 1983 and 1995 showed evidence of low molecular weight proteinuria in 1983 (retinol binding protein $>42 \mu \mathrm{g} / \mathrm{mmol}$ creatinine, laboratory reference range). Thus it was interesting to investigate whether renal function showed any evidence of deterioration or stabilisation with improvements in exposure conditions.

\section{Methods}

In vivo measurement of cadmium by neutron activation analysis is well established. ${ }^{3}$ The equipment was assembled in 1995 to try to reproduce the system used in 1983. There was consultation between the current project team and Professor D R Chettle, who constructed the original in vivo measurement system and one of the current team (Dr S Green) had been involved in experimentation with the original system. There were differences in the irradiation system; the later measurements used a larger beryllium premoderator to reduce radiation exposure and the same irradiation system to measure both the liver and kidney. Although new calibration phantoms were used in 1995, the gradients of the kidney calibration line for in vivo measurement were similar between the 1983 and 1995 system (1.45 v 1.51 (0.06) counts $\mathrm{mg} \mathrm{Cd}^{-1}$ minute $\left.^{-1}\right) .^{5}$ This level of reproduction for a single sensitivity figure within the experimental uncertainty of phantom design, irradiation geometry, and data analysis helps to confirm that the measurement systems are consistent for the kidney measurements.

Urinary cadmium and whole blood cadmium were measured by electrothermal atomic absorption spectrometry (ET-AAS) with similar methodology between 1983 and 1995. The laboratory has participated in a monthly blood cadmium external quality assurance scheme over the period of both in vivo investigations, and this showed no evidence of a change in bias.

Urinary retinol binding protein was measured by enzyme linked immunosorbent assay. ${ }^{6}$ Similar methods to those established before 1983 were used to measure urinary total protein, albumin, $\mathrm{N}$-acetyl glucosaminidase, creatinine, serum creatinine, fractional excretion of calcium, phosphate, and urate. Lyophilised urine and serum quality control material stored at $-20^{\circ} \mathrm{C}$ which was used in the 1983 study were available for reanalysis in 1995. They showed no systematic shift in measurement between investigations in 1983 and 1995.

Nine jig makers were investigated in 1995 who had been investigated in 1983 . The mean (SD, range) age of the subjects in 1995 was 53.6 (9.9, 38-66). Ethical approval was gained for the 1995 study and subjects gave informed 
Table 1 continued

\begin{tabular}{llll} 
Fe urate\% & Tot. Prot $(U)$ & Alb $(U)$ & NAG $(U)$ \\
\hline 9.5 & 15.7 & 1.7 & 0.8 \\
10.8 & 10.3 & 1.6 & 0.44 \\
12.7 & 65.1 & 4.9 & 1.1 \\
15.9 & 34.8 & 7.2 & 1.66 \\
10.8 & 17.0 & 0.9 & 0.2 \\
17.8 & 9.8 & 0.4 & 0.95 \\
18.6 & 38.7 & 4.0 & 1.3 \\
18.1 & 11.0 & 1.3 & 0.55 \\
15.9 & 96.4 & 13.4 & 2.3 \\
21.1 & 40.3 & 5.7 & 1.33 \\
9.1 & 26.0 & 3.4 & 0.7 \\
5.0 & 13.9 & 1.3 & 0.7 \\
- & 44.0 & 4.5 & 4.4 \\
13.1 & 12.9 & 0.7 & 1.0 \\
8.0 & 20.2 & 2.8 & 1.1 \\
10.8 & 13.4 & 0.9 & 0.53 \\
13.1 & 29.7 & 5.3 & 2.4 \\
11.0 & 22.9 & 1.8 & 0.65 \\
12.2 & 39.2 & 4.54 & 1.59 \\
$(8.0-18.6)$ & $(15.7-96.4)$ & $(0.9-13.4)$ & $(0.2-4.4)$ \\
11.8 & 29.7 & 4.0 & 1.1 \\
13.8 & 18.8 & 2.32 & 0.87 \\
$(5.0-21.1)$ & $(9.8-40.3)$ & $(0.4-7.2)$ & $(0.44-1.66)$ \\
13.5 & 13.4 & 1.3 & 0.7 \\
0.31 & $<0.01$ & 0.039 & 0.148 \\
\hline
\end{tabular}

consent. Blood and urine samples were collected on the same day as the in vivo cadmium measurements.

\section{Results}

CHANGES IN RENAL FUNCTION

The table shows changes in parameters of renal function. Of the nine subjects investigated on both dates, eight subjects showed evidence of low molecular weight proteinuria in 1995. Six of these were abnormal in 1983 . Three of the subjects showed abnormally increased fractional excretion of calcium $(>3.5 \%)$ at both investigations. Three of the nine subjects had slightly raised concentrations of plasma creatinine suggesting a decreased glomerular filtration rate.

On a group basis urinary retinol binding protein, total protein, and albumin showed significantly increased excretion in 1995 compared with 1983 (Wilcoxon signed rank sign test $\mathrm{p}<0.001, \mathrm{p}<0.01$, and 0.04 respectively). Although there was an increase in the mean excretion of NAG, this failed to reach statistical significance by rank sign. Six of nine subjects showed evidence of low molecular weight proteinuria in 1983; by 1995 eight of nine of the cohort had urinary retinol binding protein concentrations greater than our laboratory reference range.

The renal handling of calcium, phosphate, and urate have all been reported as showing abnormality in subjects with renal damage induced by cadmium. This is due to interference in the renal proximal tubular mechanisms for reabsorption of these three analytes. The fractional excretion of calcium, phosphate, and urate was found to be not significantly worse in 1995 than in 1983 ( $\mathrm{p}<0.05$ by signed rank test). Three of the workers with the highest urinary retinol binding protein results showed consistently increased fractional excretion of calcium at both time points. With serum creatinine as a measure of glomerular filtration rate, no significant change in this variable over the 12 year period was noted ( $\mathrm{p}=0.84$ signed rank test).
These analyses suggested an increase in proteinuria, as measured by two specific proteins and total protein. Other analytes which undergo proximal tubular reabsorption did not show a statistical decrement in function. Although there was no age matched control group with which to compare any results, the mean increases in urinary total protein, albu$\mathrm{min}$, and retinol binding protein seemed to be greater than would be expected from any normal age related changes over the 12 year period. For albumin and total protein the increases were about what would be expected from the normal reference range.

BLOOD AND URINARY CADMIUM MEASUREMENTS OVER THE STUDY PERIOD

The table shows the blood and urine cadmium concentrations at the time of the in vivo measurements. Significant decreases in both were found. The average decreases in blood and urinary cadmium concentrations over the 12 year period from 1983 were $44 \%-40 \%$.

Changes in urinary and blood cadmium over the period January 1982 to October 1995 for the workers are shown in figures 1 and 2. To investigate the influence of decreased exposure on changes in blood and urinary concentrations on a group basis, measurements for an individual subject were normalised to their respective concentration at the in vivo measurement in 1983. These normalised results within a 3 monthly period were averaged (figs 3 and 4). The data suggested a rapid drop in blood cadmium for the first 5 years after the 1983 measurement, after this time the decrease in blood cadmium over time slows considerably. Conversely for urinary cadmium, there was no evidence of a decrease

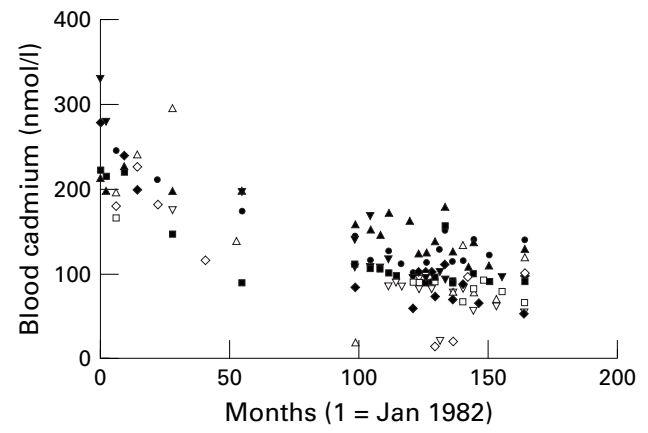

Figure 1 Measured blood cadmium concentrations in the nine jig makers.

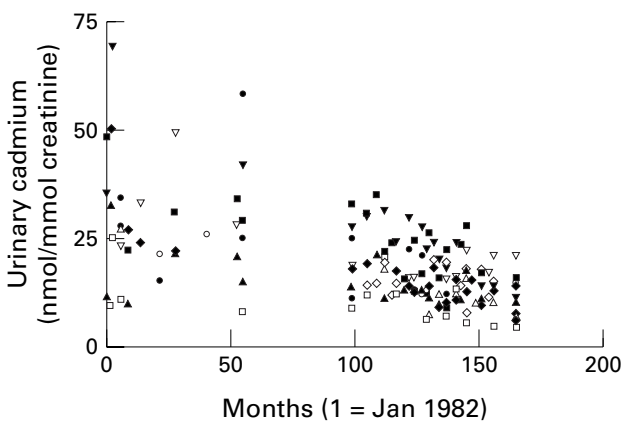

Figure 2 Measured urinary cadmium concentrations in nine jig makers. 


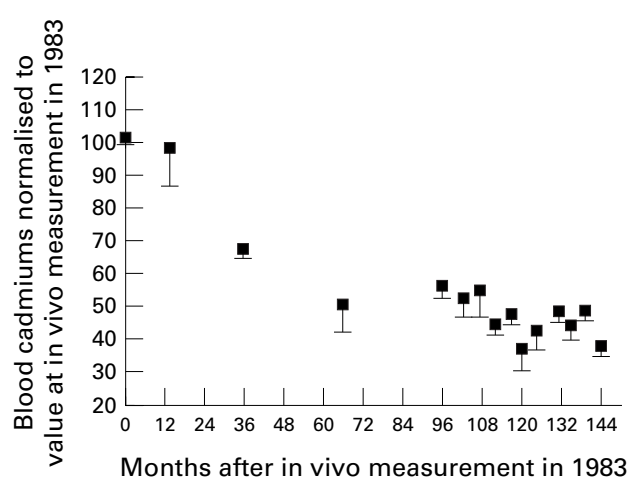

Figure 3 Normalised blood cadmium results. Each blood result for a worker was expressed as a percentage of their blood cadmium concentration at the time of the in vivo measurement in 1983. These normalised results for all subjects were averaged within 3 month periods and mean (SEM) was expressed as a downward bar at the midtime point of the 3 month period.

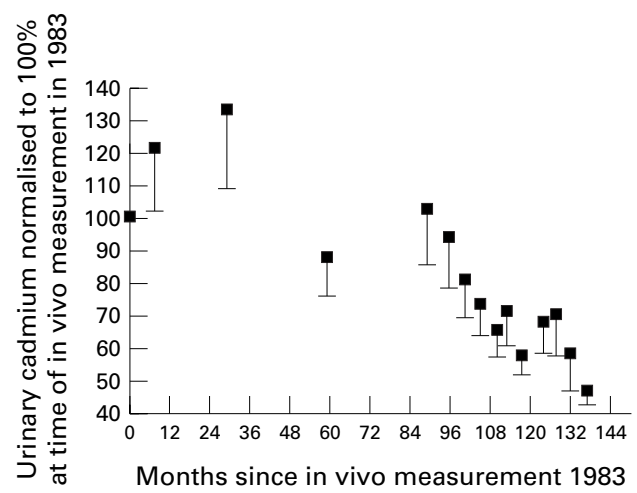

Figure 4 Normalised urinary cadmium results. Each urinary cadmium result for a worker was expressed as a percentage of his urinary concentration at the time of the in vivo measurement in 1983. These normalised results for all subjects were averaged within 3 month periods and mean (SEM) was expressed as a downward bar at the midtime point of the 3 month period.

in concentrations over the first 7.5 years; but in the later period between the two in vivo investigations there was clear evidence of a decrease of urinary cadmium. In the last 4.5 years before the 1995 measurement the mean urinary cadmium decreased by about $50 \%$.

IN VIVO MEASUREMENTS OVER THE STUDY PERIOD There was no apparent change in kidney cadmium concentration in the group between the measurements in 1983 and 1995. The average decrease in liver cadmium among the nine subjects over the 12 years was $12 \mathrm{ppm}$. With the International Commission on Radiological Protection (ICRP) reference value for liver weight of $1.8 \mathrm{~kg}$, this decrease in $12 \mathrm{ppm}$ amounts to $22 \mathrm{mg}$ of cadmium. However, the spread of individual changes in liver cadmium were between $+17.8 \mathrm{mg}$ and $-63.5 \mathrm{mg}$.

CORRELATION BETWEEN IN VIVO MEASUREMENTS AND CADMIUM CONCENTRATIONS IN BODY FLUIDS

Blood and urinary cadmium concentrations in 1995 were correlated with the in vivo measurements of liver, kidney, and the body burden of cadmium calculated with the formula:

Body burden $=\left(\operatorname{liver}(\mathrm{mg})+2{ }^{\star} \operatorname{kidney}(\mathrm{mg})\right) /$ $(0.16+0.53)$ based on data reported by Nord- berg et $\mathrm{al}^{7}{ }^{7}$ Urinary cadmium was not significantly correlated (Spearman correlation, $\mathrm{p}>0.05$ ) with cadmium concentrations in liver, kidney, or body burden. Blood cadmium was significantly correlated with body burden (Spearman $r=0.71, \mathrm{p}=0.037$ ), but it just failed to show a significant correlation with urinary cadmium concentrations (Spearman $r=0.617$, $\mathrm{p}=0.086$ ), liver cadmium (Spearman $r=0.55$, $\mathrm{p}=0.13$ ), and kidney burden (Spearman $r=0.65, \mathrm{p}=0.066)$.

Data from the initial in vivo and body fluid measurements in 1983 had shown a significant correlation between urinary and blood cadmium (Spearman $r=0.78, \mathrm{p}=0.017$ ). Urinary cadmium was not significantly correlated with liver cadmium (Spearman $r=0.60, p=0.097$ ) or kidney cadmium (Spearman $r=0.20, \mathrm{p}=0.61$ ). Blood cadmium was not significantly correlated with liver (Spearman $r=0.30, \mathrm{p}=0.44$ ) or kidney cadmium (Spearman $r=0.02, p=0.98$ ).

RELATION BETWEEN CUMULATIVE LOSSES OF URINARY CADMIUM AND CHANGES IN IN VIVO MEASUREMENTS BETWEEN 1983 AND 1995 The serial urinary cadmium concentrations in subjects allow estimation of the total cadmium excreted in the 12 year period by calculating the area under the urinary cadmium time curve, assuming that a subject excretes on average $15 \mathrm{mmol}$ creatinine a day. The mean total excretion of cadmium in the 12 year period between the in vivo measurements was $133(\mathrm{SD}=47) \mathrm{mg}$ cadmium. In the last 5 years of this period the mean total excretion was 50 $\mathrm{mg}(\mathrm{SD}=16)$. This represents a substantial excretion of the metal which is not reflected by the in vivo measurements.

\section{Discussion}

The data from this study suggest that the proteinuria induced by excessive exposure to cadmium is not reversible even if exposure to the metal is greatly reduced. Estimates with urinary total protein, albumin, and retinol binding protein showed evidence on a group basis of significant increases in the 12 years from the initial study. This finding contrasts with the report of Roels et $a l^{8}$ who found evidence of the reversibility of tubular proteinuria when the proteinuria was mild, but it is in agreement with Jarup et $a l^{9}$ and Elinder et $a l^{10}$ who reported irreversible tubular dysfunction. The fractional clearance of calcium, phosphate, and urate, which reflect specific renal tubular reabsorptive mechanisms, did not show any worsening over time. Serum creatinine did not show any evidence of an increase over the 12 year period, but it is recognised that serum creatinine is not a sensitive marker of small changes in glomerular filtration rate. ${ }^{11}$ Therefore it is possible that small but significant decrements in glomerular filtration rate have occurred undetected.

It is well recognised that blood cadmium is an indicator of current or recent exposure; but the influence of body burden on blood cadmium may sometimes be overlooked. The half life of blood cadmium after the end of exposure has been reported to be 3-4 
months. ${ }^{12}$ However, some compartment of blood cadmium is said to reflect body burden and may become dominant in workers who ended exposure a long time previously. $\mathrm{McDi}$ armid et $a l^{13}$ studied 16 workers removed completely from exposure to cadmium and noted a relatively rapid decline in the first $2-5$ months of exposure but without return to normal blood values after 20 months, and a variable rate of decline between people. Jarup et al ${ }^{9}$ investigated 46 workers with high historical exposure which had stopped in 1978; in 1984 and 1993 blood cadmium was a good indicator of dose by contrast with urinary cadmium concentrations.

The data in our study confirm the potential influence of both recent and historical exposure on blood cadmium concentrations. Mean, normalised blood cadmium concentrations are noted to decrease to $50 \%$ of the value found at the initial time of in vivo investigation in 1983. This coincides with the period when exposure to cadmium was being severely limited by control measures and substitution by cadmium free solder. After 1988 (month 60 in fig 3) the normalised blood cadmium concentrations is very reduced and exposure to cadmium would be low, being restricted to repair of any of the decreasing number of jigs with old solder containing cadmium. In 1995, when exposure to cadmium had effectively ended years earlier, blood cadmium was statistically correlated with cadmium body burden and just failed to reach significance with liver and kidney cadmium concentrations. However, in 1983 correlations between blood cadmium and liver, kidney and body burden were non-significant and lower than in 1995, reflecting the influence on blood cadmium of recent exposure at the earlier time and body burden later. The mean blood cadmium concentration in the nine workers was still $90 \mathrm{nmol} / 1$ in 1995, having reduced from $205 \mathrm{nmol} / \mathrm{l}$ in 1983. The value of $90 \mathrm{nmol} / 1$ has been used by many occupational physicians in the United Kingdom for several years as an unofficial trigger for further hygiene and health investigation in currently exposed workers undergoing routine biological monitoring. The data suggest the importance of considering the historical cumulative exposure to cadmium in interpreting blood cadmium concentrations, particularly in subjects without exposure to cadmium for some time. It also has implications for managing a strategy for removing or readmitting workers to potential exposure to cadmium at work based on blood cadmium monitoring data.

Urinary cadmium is said to reflect the kidney or body burden, but is also influenced by on going exposure and damage to the kidneys. ${ }^{12-14}$ The normalised urinary cadmium concentrations in our cohort showed no significant decrease for the first 7 years after the initial in vivo measurement in 1983, even though atmospheric exposures had been reduced during this period (1983-90) and was being reflected in concomitantly decreased blood cadmium concentrations. The last 5 years of the period between the in vivo measurements (1990-5) showed a significant decrease by $50 \%$ in normalised urinary cadmium concentrations. Exposure of the subjects to cadmium was constantly low over this period of declining urinary concentrations. This decline would likely reflect the body burden. The mean urinary cadmium concentration in 1995 even after several years with very low potential exposure to cadmium was $11.8 \mathrm{nmol} / \mathrm{mmol}$ creatinine; this is higher than the concentration of $10 \mathrm{nmol} / \mathrm{mmol}$ creatinine often historically used in the United Kingdom as a trigger to take intervention in workers undergoing routine biological monitoring. ${ }^{15}$ Interestingly at neither time was urinary cadmium related to kidney cadmium concentration. These findings may reflect the influence of kidney damage on weakening any relation between urinary cadmium concentrations and kidney cadmium. Therefore care has to be taken in interpreting urinary cadmium concentrations as a simple index of body burden, or specifically kidney cadmium burden.

The potential complex relation between urinary and blood cadmium concentrations and exposures could be unravelled by in vivo measurement of cadmium in the liver and kidney which are major storage organs. However, the measurements in this study seem to leave some questions unanswered. The mean loss of cadmium in the liver ( $22 \mathrm{mg}$ ), calculated body burden $(33 \mathrm{mg})$ and apparent no mean loss in kidney cadmium is at odds with the mean total excretion of cadmium $(133 \mathrm{mg})$ in urine over the 12 year period, if urinary cadmium reflects body burden. There are few studies reported on longitudinal in vivo cadmium measurements which shed light on the relation between blood and urinary cadmium, and body burden. Armstrong et al found a complex pattern of liver and kidney cadmium concentrations over a 9 year period in a study of smelters exposed to cadmium. ${ }^{16}$ However, a general substantial decrease in body burden of cadmium was found which mirrored the reduction of exposure to cadmium used by the firm and was greatest in those subjects who had retired.

There may be several possible explanations for the differences between measured in vivo concentrations and urinary cadmium loss in our study. Firstly, error in in vivo measurements or uncertainty in the calculated cumulative cadmium excretion. Care was taken to ensure that the in vivo measurement system in 1995 was as equivalent as possible to the 1983 measurements and it is unlikely that any bias in the neutron activation measurements would introduce an error of such magnitude; secondly, that some concurrent exposure to cadmium is being reflected in the calculated urinary excretion. Although decreasing from known high exposures before 1983, the occupational hygiene would suggest that there was still some considerable exposure to cadmium for about 2 years after 1983 . This situation may be reflected by the apparent exponential decrease in blood cadmium measurements after 1983 but that the exposure after 1983 may have been enough to maintain the relatively constant urinary cadmium concentrations for about 5 years after 1983. This 
would substantiate the view that a component of urinary cadmium is related to recent exposure, particularly in people with tubular dysfunction. Thirdly, that there is a soft tissue cadmium storage compartment in those with high chronic exposure which is unaccounted for. Cadmium loss from such a compartment would have to have a shorter half life than that in the liver or kidney but its existence would refute the calculation of body burden used in this paper. However, the distribution between kidney, liver, and other tissues has been defined from data in subjects exposed to low concentrations of cadmium through dietary sources. ${ }^{7}$ Muscle, which constitutes $40 \%$ of body weight, has a relatively low cadmium concentration in environmental exposure and cadmium in muscle seems to have a longer half life than that in liver or kidney. ${ }^{17}$ The lungs of smokers have been shown to have higher cadmium concentrations than in non-smokers, but there seems to be no recent necropsy data on cadmium concentration in lungs or other organs for highly exposed workers in whom substantial accumulation could potentially occur. The calculation of body burden by an extrapolation from low to higher exposure scenarios of concentrations in relevant tissues may be erroneous.

The data reinforce the idea that in those subjects without any recent exposure, blood cadmium concentrations will increasingly reflect body burden of cadmium and that after removal from exposure to cadmium, urinary and blood cadmium concentrations decline slowly. In subjects with substantial historical exposure, concentrations are unlikely to approach normal values. Interpretation of urinary cadmium concentrations in those with evidence of tubular proteinuria is complex. Therefore in those workers with potential exposure to cadmium a biological monitoring strategy should be aimed at keeping urinary or blood cadmium concentrations below suggested concentrations over a working lifetime, such that renal and other effects are avoided. In those workers who have had substantial historical exposure, a different strategy may need to be applied, and for those subjects with evidence of renal tubular dysfunction removal from any further exposure is possibly warranted due to the slow progression of the dysfunction.

1 Health and Safety Executive. Occupational exposure limits 1997. Sudbury, Suffolk: HSE Books, 1997.

2 Smith N, Topping M, Stewart J, et al. Occupational cadmium exposure in jig solderers. Br f Ind Med 1986;43: 663-6.

3 Chettle D, Armstrong R, Todd A, et al. Measurement of trace elements in-vivo. In: Yasumura S, ed. Advances in in-vivo body composition studies. New York: Plenum Press, 1990.

4 Morgan W, Ryde S, Jones S, et al. In-vivo measurement of cadmium and lead in occupationally exposed workers and an urban population. In: Schrauzer G, ed. Biological trace element research. Totowa, NJ: Humana Press, 1990.

5 Armstrong R. Studies relating to the in-vivo measurement of cadmium and mercury $[\mathrm{PhD}$ thesis]. Birmingham: Univercadmium and mercury [Ph]

6 Topping M, Forster H, Dolman C, et al. Measurement of urinary retinol binding protein by enzyme linked immunosorbent assay and its application to the detection of tubular proteinuria. Clin Chem 1986;32:1863-6.

7 Nordberg G, Kjellstrom T, Nordberg M. Exposure, dose and metabolism. In: Friberg L, Elinder C-G, Kjellstrom T, eds. Cadmium and health: a toxicological and epidemiolgical appraisal. Vol 1. Boca Raton: CRC Press, 1985;103-78.

8 Roels H, Assche F, Oversteyns M, et al. Reversibility of microproteinuria in cadmium workers with incipient tubuar dysfunction after reduction of exposure. Am f Ind Med 1997;31:645-52.

9 Jarup L, Persson B, Elinder C-G. Blood cadmium as an indicator of dose in a longterm follow-up of workers previously exposed to cadmium. Scand $\mathcal{F}$ Work Environ Health 1997;23:31-6.

10 Elinder C-G, Edling C, Lindberg E, et al. $\beta-2-$ Microglobulinuria among workers previously exposed to cadmium: follow-up and dose-response analyses. $A m \mathcal{F}$ Ind Med 1985;8:553-64.

11 Black D, Cameron J. Renal function: tests used in the investigation of renal disease. In: Brown S, Mitchel F, Young D, eds. Chemical diagnosis of disease. Amsterdam: Elsevier, 1980;483-505.

12 Jarup L, Rogenfelt A, Elinder C-G, et al. Biological half-life of cadmium in the blood of workers after cessation of expoof cadmium in the blood of workers after cessation

13 McDiarmid M, Freeman C, Grossman E, et al. Follow-up of biologic monitoring results in cadmium workers removed from exposure. Am F Ind Med 1997;32:261-7.

14 Elinder C-G, Gerhardsson L, Oberdorster G. Biological monitoring of toxic metals: overview. In: Clarkson T, Friberg L, Nordberg L, et al, eds. Biological monitoring of toxic metals. New York: Plenum Press, 1988;1-71.

15 Adams R. Manufacturing process, resultant risk profiles and their control in the production of nickel-cadmium batteries. Occup Med 1992;42:101-6.

16 Armstrong R, Chettle D, Scott M, et al. Longitudinal studies of exposure to cadmium. Br f Ind Med 1992;49:556-9.

17 Elinder CG. Normal values for cadmium in human tissue, blood, urine in different countries. In: Friberg L, Elinder C-G, Kjellstrom T, et al, eds. Cadmium and health: a toxicological and eidemiological appraisal. Boca Raton: CRC Press, 1985;81-102. 